\title{
LA TIPOLOGIAA Y EL ACENTO PREHISTÓRICO LATINO
}

Typological data do not furnish evidence in support of the hypothesis of a change in Latin from prehistorical initial stress to historical (ante)penultimate stress.

Según la tesis tradicional, entre el acento indoeuropeo, verosímilmente móvil, y el acento latino clásico, también móvil, hubo un estadio en el que la lengua latina dispuso de un acento fijo en sílaba inicial ', el cual explicaría las alteraciones cualitativas de las vocales interiores breves latinas (fäcio - inficio) o incluso su desaparición ( ${ }^{*}$ sub-răpio $>$ surpio). Desde el punto de vista tipológico a tal tesis podrían formulársele las siguientes seis objeciones (en orden de menor a mayor importancia):

1. Sobre el que las alteraciones cualitativas de las vocales o incluso su desaparición se produzcan en posición átona. No se sigue necesariamente que sólo las vocales átonas padezcan alteraciones tímbricas o incluso desaparezcan, ni que el acento pueda preservarlas. Por el contrario, para algunos cambios parece no haber explicación otra que la acción del acento.

1.1. El cambio cualitativo de vocales a causa precisamente de la naturaleza tónica de estas aparece documentado en muchas lenguas. Basten ejemplos como el paso ['je > 'jo] en ruso (grafema <è >) o la característica diptongación de ['i] tónica (> ['aj/aj]) en algunos dialectos orientales del guego albanés. En otro orden y entre varios cambios afines, en irlandés moderno una vocal tónica originalmente neutra recibe el timbre de la vocal de la primera sílaba (furasta 'fácil', / furssta $>$ for'usta $>$ frusta/) ${ }^{2}$. En fin, en dálmata, por lo general, todas las vocales tónicas se diptongan o alteran de algún modo. Así, ['a(:)] pasa a ['wo] (capram > kuobra), ['wa] (barbam > buarba) o ['u] (placet > pluk), pero si es átona se conserva.

\footnotetext{
1 La teoria fue formulada por A. Dietrich, «Zur geschichte des accents im lateinischen», $K Z$ 1, 1852, pp. 543-69.

2 Vid. M. O Siadhail, Modern Irish. Grammatical structure and dialectal variation, Cambridge 1989, p. 28.
} 
1.2. En circunstancias especiales puede producirse incluso la deleción de una vocal tónica, como en muchas desinencias lituanas (Lietuvojè > Lietuvõj «en Lituania»).

2. Sobre la uniformidad del modelo con acento fijo. Aunque existen lenguas (indoeuropeas) con acento fijo ya en sílaba inicial (checo, eslovaco), en antepenúltima (macedonio), en penúltima (polaco) o en final (francés), el tipo de acento fijo absoluto no es tan frecuente. En algunas lenguas consideradas de acento fijo se producen, además, interferencias de carácter diverso. En polaco, por ejemplo, aparte de préstamos, antiguos compuestos como formas verbales o numerales presentan acento en la antepenúltima. En macedonio, además de los préstamos, que pueden presentar una posición excepcional, los gerundios reciben acento en la penúltima.

2.1. Tampoco en el latín clásico, que presenta una organización de la posición acentual bastante clara, falta algún tipo de interferencia, ya que los compuestos con la enclítica — que presentan acento en la penúltima sea cual sea la cantidad de esta sílaba (ros'ăque).

2.2. No es infrecuente aquella situación donde el acento viene gobernado por un complejo de factores fonéticos y gramaticales. Tópico ejemplo de complejidad sería el lituano, donde la posición del acento viene determinada por factores semánticos, fonológicos, morfológicos y etimológicos ${ }^{3}$. En esta lengua, por ejemplo, puede a veces darse retracción del acento al prefijo verbal, así ima 'toma(n)', pero àtima 'saca(n)' (cf. lat. emit - eximit).

3. Sobre la estabilidad de las vocales iniciales. No es necesariamente indicio de que sean tónicas las vocales iniciales por ser las únicas no afectadas por la apofonía.

3.1. Pueden haberse producido presiones morfológicas o léxicas. Considérese que para muchas formas la apofonía, de haberse producido también en sílaba inicial, habría obscurecido su significado (formas como ămamus - ĕmamus habrían resultado idénticas).

3.2. La dinámica de la palabra hace mucho más estable fonéticamente la parte inicial que las otras $\mathrm{y}$, en consecuencia, suele hacer más estables las sílabas protónicas que las que siguen al acento. La alteración o pérdida de vocales y hasta sílabas finales e interiores es mucho más frecuente que la alteración o pérdida de vocales o sílabas iniciales, como evidenciaría la historia

3 Vid. B. Stundžia, «On the accentual classification of primary declinable words of Standard Lithuanian», $\operatorname{LgB} 1$ 1, 1992, pp. 71-83; y para una exposición histórica más detallada N. van Wijk, Die baltischen und slavischen Akzent- und Intonationssysteme. Ein Beitrag zur Erforschung der baltisch-slavischen Verwandtschaftsverhältnisse, La Haya $1958_{2}$. 
de muchas lenguas indoeuropeas. Así, en el portugués de Brasil las siete vocales tónicas quedan reducidas en posición átona a cinco vocales antes del acento, pero a tres tras el acento.

4. Sobre la inserción de un estadio con acento fijo entre dos estadios móviles. No parece que haya documentada en lengua alguna un proceso de tal tipo (móvil - fijo - móvil), ni, en concreto, un cambio tan rápido y radical de un sistema muy simple (fijo en inicial) a uno relativamente complejo (móvil según básicamente la cantidad de la penúltima sílaba).

4.1. La tesis del acento fijo no proporciona explicación alguna para el paso a un sistema tan distinto y estructurado como el del latín clásico y donde operan tendencias otras y opuestas. Siendo la situación latina clásica congruente con lo que suponemos para el indoeuropeo (acento móvil), habría que explicar cómo por un período de tiempo se produce esa anómala interrupción de la tendencia; o bien, si se heredó yá un acento fijo, cómo repentinamente se vuelve a una situación tan indoeuropeoide.

5. Sobre la relación del acento fijo y la apofonía. En el ámbito indoeuropeo la apofonía propiamente dicha se da en lenguas con acento móvil. Lenguas apofónicas como catalán, portugués, esloveno, ruso, búlgaro oriental, ucraniano y bielorruso tiene acento móvil. Parece que un acento fijo pertubaría el reconocimiento de las formas y la solidaridad del paradigma. En cat. peg'ar y pag'ar no se distinguen fonéticamente, es fundamentalmente la movilidad del acento (por ejemplo, p'ego y $p^{\prime}$ 'ago) la que hace posible el mantenimiento de dos grupos léxicos diferentes que con acento fijo habrían terminado por ser indistinguibles.

6. Sobre la inmunidad de las vocales largas átonas. Extraña que un acento fijo, habiendo afectado al timbre de las vocales átonas y aun según se hallen en silaba cerrada o abierta (inficio, infectus), no haya producido abreviaciones en las vocales largas átonas, teóricamente más débiles. En esloveno (con acento móvil y «musical») no sólo las vocales átonas son apofónicas, sino que sólo pueden ser breves. Al menos en las lenguas indoeuropeas, en posiciones átonas la alteración cuantitativa parece un fenómeno más común (o incluso previo) que la alteración cualitativa. No conocemos de lengua cuantitativa alguna que, como en la situación supuesta para el latín prehistórico, haya sufrido sólo alteraciones cualitativas.

6.1. Tipológicamente está muy extendida la tendencia a equivalencias del tipo tónica - larga y átona - breve y a evitar tónica — breve y átona - larga (en ese sentido el tipo eslovaco nemý 'mudo' es infrecuente). La atracción del acento por una vocal larga o el alargamiento de una breve tónica es un fenómeno muy común. El eslovaco posee acento fijo inicial y vocales largas o breves, no es empero 
apofónico, aunque sí experimenta abreviamientos de largas átonas. Dos vocales largas consecutivas no son, por lo general, toleradas en una misma palabra, de modo que la vocal larga subsecuente es abreviada (krásný > krásny 'bello') ${ }^{4}$. En sueco toda sílaba tónica es larga. En maltés, islandés, guego albanés, cómico medio, en gaélico escocés en general o en esloveno la cantidad (ya) no es distintiva en las vocales átonas. En serbocroata la cantidad vocálica protónica se neutraliza ${ }^{5}$. En irlandés moderno una vocal larga átona como en scadán ('arenque') permanece larga en el habla de Connacht, pero es abreviada en la del Ulster y atrae el acento en la de Munster 6; así en esta región el acento inicial pasa a una vocal larga en formas con estructura $\breve{V} \bar{V}$ (corc'án 'tarro'), $\breve{V} \bar{V} \bar{V}$ (cail'in' 'chavalas') o $\breve{V} \breve{V} \vec{V}$ (spealad'oir 'segador') ${ }^{7}$. En huasteco (lengua maya) el acento viene asignado en principio a la última vocal larga, y sólo si no hay vocal larga, a la primera vocal ${ }^{8}$. En pandjabi (lengua indoeuropea del Punjab) el acento se sitúa sobre una sílaba interior con vocal larga y sólo en inicial de no darse vocal larga alguna. También en chemeris oriental (lengua fénnica volgaica) el acento se sitúa en inicial sólo a falta de sílabas largas. No parece que haya lenguas que sólo distingan largas y breves en posición átona.

6.1.1. Habría manifestaciones de esta tendencia en épocas históricas documentadas del latín. Esto supondría que en época prehistórica la prosodia latina habría presentado una tendencia opuesta a la que inmediatamente se dará.

6.1.1.1. Un acento fijo se contradiría en su esencia con la tendencia que opera, algo después, en latín clásico donde se favorece el acento en posiciones de vocal larga ('inuënit pero 'inu' énit).

6.1.1.2. Aquella tendencia opera en la correptio iambica (bënē $>$ bĕnĕ), el fenómeno se extiende al caso de dos monosílabos unidos en el discurso, a la primera sílaba de un polisílabo cuando sigue a un monosílabo y a cualquiera de las dos sílabas que preceden al acento en un tetrasílabo. Esta extensión indica que, más allá del concreto fenómeno de la correpción yámbica y de sus particulares condicionantes, es posible intuir una misma tendencia general. Ya

\footnotetext{
${ }^{4}$ Lógicamente los diptongos se comportan como conteniendo una vocal larga (piatý > piaty 'quinto'), una vez que en eslovaco tenemos las siguientes correspondencias en las formas nativas: [i-i:, u-u:, a-a:, e-je, o-wo, $\mathfrak{x - j}$-j].

${ }^{5}$ Esto contradiría en principio lo expuesto en 3.2 , pero hay que tener en cuenta que la oposición cuantitativa resulta ser relevante en muchas desinencias (žène gen. sing. - žène nom. plur. de žèna' 'mujer').

6 Vid. G. Mac Eoin, «Irish», en M. J. Ball-J. Fife, The Celtic Languages, Londres-Nueva York 1993, p. 105.

7 Vid. Ó Siadhail, Modern Irish... cit. en n. 2, p. 29.

8 Escribe J. Durand (Generative and Non-Linear Phonology, Londres-Nueva York 1990 , p. 222) al respecto: «This is not untypical and, indeed, many languages tend to favour closed syllables, long or tense vowels, diphthongs, full vowels as foot heads and downgrade open syllables, short or lax vowels».
} 
J. B. Greenough ${ }^{9}$ indicó que todas estos hechos podían ser explicados como para evitar que una sílaba breve tónica fuere seguida por una larga átona. De modo que de cuatro teóricas posibilidades, ' $\breve{V}-\breve{V}, ' \bar{V}-\bar{V}, ' \bar{V}-\bar{V}, ' \grave{V}-\vec{V}$, sólo la última tendió a evitarse. Parecidamente en el celta de Man en disílabos se abrevia la segunda vocal (átona) si la primera (tónica) es breve. E, inversamente, al atraer un sufijo con vocal larga el acento, la vocal de la sílaba inicial (ahora átona) se abrevia ${ }^{10}$.

6.1.1.3. La teoría del acento fijo resultaría también contradictoria con las tendencias que vemos en latín tardío y con los datos expuestos por S. Kiss " Las sílabas abiertas en latín clásico (el 53 por 100) contienen tres veces más vocales largas que las sílabas cerradas. Hay un 21,6 por 100 de sílabas abiertas largas frente a un 7,6 por 100 de sílabas cerradas con vocal larga y «ce sont les syllabes ouvertes à voyelle longue qui sont les plus aptes à attirer l'accent de mot en latin» ${ }^{12}$,

6.2. Aunque para vocales breves, la existencia de síncopas en diversas fases de la historia del latín (surpio, saecla) manifestaría la tendencia a alteraciones cuantitativas.

6.2.1. La tesis del acento fijo no explica por qué esas alteraciones se habrían producido sólo como deleciones de vocales breves (surpio) y no como abreviamientos de vocales largas (amicus). Ilustrativa (de lo que esperaríamos) puede resultar la comparación con el letón, lengua con acento inicial y vocales largas y breves. En posición átona las vocales [a e i] desaparecieron en sílaba final (vilks 'lobo', lit. vĩ kas), los diptongos monoptongaron (saku 'digo', lit. sakaũ) y las vocales largas ([a: e: i: u:]) se abreviaron (bite 'abeja', lit. bité). La situación fue similar en el prenórdico germánico: con el acento inicial muchas vocales breves desaparecieron y las largas se abreviaron.

Se puede concluir que, aunque resulten tipológicamente aceptables los presupuestos teóricos en los que se basa la tesis que para el latín prehistórico postula un acento fijo en inicial, dichos presupuestos no imponen necesariamente la descripción obtenida, la cual resulta tipológicamente anómala, sin que se justifique o se propicie justificación de sus anomalías.

\section{BALLESTER}

\footnotetext{
${ }^{9}$ En «Early Latin Prosody», HSPh 5, 1894, p. 62.

${ }^{10}$ Vid. G. Broderick, «Manx», en The Celtic... cit. en n. 6, p. 236.

11 En Les transformations de la structure syllabique en latin tardif, Debrecen 1972.

12 A lo que Ch. Touratier (rec. de Kiss, Les transformations..., BSL 8, 1973, p. 151) comenta: «certains évolutions du latin tardif son déjà plus ou moins inscrites dans la structure du latin classique; c'est dès le latin classique que la syllabe ouverte est privilégiée et qu'apparait l'affinité entre l'accent et la quantité vocalique qui est la cause de l'isochronic phonologique du latin tardify.
} 